\title{
PROFESSORAS QUE ENSINAM MATEMÁTICA E UM DENOMINADOR COMUM: Grupo Colaborativo
}

\author{
Marcielli de Lemos Cremoneze ${ }^{1}$ \\ Klinger Teodoro Ciríaco²
}

\begin{abstract}
RESUMO
Analisamos o movimento da constituição de um grupo de trabalho colaborativo, especificamente o papel do processo de reflexão sobre a prática oportunizada pelo registro reflexivo de duas integrantes a partir da fotografia e da videogravação das aulas de Geometria. O referencial teórico abarca questões ligadas à aprendizagem do professor que ensina Matemática no ambiente dos grupos colaborativos, bem como do processo de sua formação continuada com base na prática reflexiva. A metodologia adotada inscreve-se no campo dos estudos qualitativos, de caráter descritivo-analítico, em que a experiência releva características da colaboração no espaço de discussão coletiva como sendo um aspecto promissor dos procedimentos de produção de dados. Os resultados finais permitem fazer a inferência de que as docentes tiveram suas práticas modificadas a partir do direcionamento das atividades propostas no grupo com base na dinâmica de registrar e compartilhar as aulas, questão central que levantou a necessidade de escrever, narrar e/ou gravar a própria atuação como fonte de desenvolvimento profissional. Esse dado trouxe, ainda, a compreensão de que, no compartilhar das ações, o sujeito se reconhece como protagonista de sua atividade e pode contribuir com o fazer do outro, corroborando a assertiva "o que falta em mim sobra em você".
\end{abstract}

Palavras-chave: Educação matemática. Grupo colaborativo. Reflexão sobre a prática.

\section{TEACHERS WHO TEACH MATHEMATICS AND A COMMON DENOMINATOR: COLLABORATIVE GROUP}

\section{ABSTRACT}

We analyze the movement of the constitution of a collaborative work group, specifically, the role of the process of reflection on the practice, opportunized by the reflective recording of two members from the photography and video recording of the Geometry classes. The theoretical reference covers questions related to the teacher's learning that teaches Mathematics in the environment of the collaborative groups, as well as the process of their ongoing formation based on reflective practice. The methodology adopted falls within the field of qualitative, descriptive-analytical studies, in which experience reveals characteristics of collaboration in the collective discussion space as a promising aspect of data production procedures. The final results allow us to infer that teachers had their practices modified from the direction of the activities proposed in the group based on the dynamics of registering and sharing classes, a central issue that raised the need to write, narrate and / or record their own performance as a source of professional development. This fact has also brought to the understanding that in the sharing of actions, the subject recognizes himself as the protagonist of his activity and can contribute to the doing of the other, corroborating the assertion "what is lacking in me is left in you."

Keywords: Mathematics education. Collaborative group. Reflection on practice.

Recebido em: 14/10/2019

Aceito em: 26/10/2019

\footnotetext{
${ }_{1}$ Mestra em Educação Matemática pelo Instituto de Matemática (PPGEdumat) da Universidade Federal de Mato Grosso do Sul - UFMS, Campo Grande, na linha de pesquisa "Formação de Professores e Currículo". Licenciada em Pedagogia pela Universidade Federal de Mato Grosso do Sul - UFMS, Campus Naviraí. Integrante do "MANCALA - Grupo de Estudos e Pesquisas em Educação Matemática, Cultura e Formação Docente" (CNPq/UFSCar). Tem experiência na área de Educação e Educação Matemática, com ênfase em Formação de Professores, Práticas Colaborativas e Ensino de Matemática. http://lattes.cnpq.br/6232737160514380. https://orcid.org/0000-0002-9787-3419. marciellicremoneze@hotmail.com

2 Professor-adjunto, em regime de Dedicação Exclusiva da Universidade Federal de São Carlos (UFSCar) no Departamento de Teorias e Práticas Pedagógicas (DTPP) do Centro de Educação e Ciências Humanas (CECH). Líder do Grupo de Estudos e Pesquisas em Educação Matemática, Cultura e Formação Docente - MANCALA (CNPq/UFSCar). É docente permanente do Programa de Pós-Graduação em Educação Matemática (Mestrado e Doutorado) da Universidade Federal de Mato Grosso do Sul (UFMS Campo Grande), atuando na linha de pesquisa "Formação de Professores e Currículo". Desenvolve estudos e pesquisas com ênfase nos seguintes temas: Interculturalidade, Psicologia da Educação Matemática, Formação de Professores, Início da Docência, Desenvolvimento Profissional e Grupos Colaborativos. http://lattes. cnpq.br/2947929641568853. http://orcid.org/0000-0003-1694-851X. ciriacoklinger@gmail.com
} 
Este texto refere-se a uma pesquisa mais alargada, desenvolvida no âmbito de um grupo de trabalho colaborativo, cujo objetivo é compreender em que medida o compartilhamento do registro da prática docente contribui para o processo reflexivo do aprender a ensinar de professoras dos anos iniciais. O ambiente direto de produção de dados refere-se ao "Grupo de Práticas Colaborativas em Educação Matemática nos anos iniciais" - GPCEMai -, vinculado à Universidade Federal de Mato Grosso do Sul - Campus Naviraí -, o qual tem como fundador ${ }^{3}$ o segundo autor.

O tema explorado no artigo poderá fornecer subsídios de cunho teórico e prático, demonstrando a relevância dos grupos colaborativos para o incentivo do registro da prática como forma de reflexão, no sentido de contribuir para que o docente reveja sobre suas ações e promova a reestruturação das aulas ao buscar elementos que possam constituir objeto de temas futuros de próximas aulas.

\section{GRUPOS COLABORATIVOS EM EDUCAÇÃO MATEMÁTICA E A APRENDIZAGEM DOCENTE}

No campo da educação são inúmeras as discussões sobre formação docente, no entanto estudos (IMBERNÓN, 2011; FIORENTINI; CRECCI, 2012; FERREIRA, 2013) mostram que muitos dos cursos de formação continuada não são totalmente efetivados no que se refere ao desenvolvimento profissional, posto que estes, muitas vezes, são organizados na perspectiva de "pacotes" com conteúdos programáticos fechados, o que impossibilita discussões e/ou articulações mais consistentes com o real trabalho dos professores em exercício.

Para Nacarato (2013), a ineficiência dessas propostas está relacionada com o modelo de formação tradicional que não considera o professor peça fundamental para a construção do seu desenvolvimento. A falta de proximidade desse espaço com a realidade possibilita certo distanciamento do professor no processo de seu desenvolvimento profissional, gerando lacunas que podem ter suas origens na formação inicial e que se perpetuam pela formação continuada.

Neste contexto, pesquisadores fomentaram buscas por outros modelos de formação que possibilitassem o envolvimento do professor em seu processo formativo de forma mais ativa e que o colocasse como protagonista de sua atividade. Para Ferreira (2013), a parceria entre a universidade e a escola é um caminho promissor para mudanças consideráveis no processo de ensino e aprendizagem da Matemática em todos os níveis. A construção de saberes articulada contribui de forma expressiva para a melhoria da prática docente.

Nesta perspectiva, os grupos colaborativos tem se destacado como ferramenta para o desenvolvimento profissional por meio de parcerias entre a Educação Básica e a universidade, com base no compartilhamento de experiências e com o intuito de reflexão sobre as práticas do aprender a ensinar e ampliar os saberes docentes (CIRÍACO; MORELATTI, 2016).

As reuniões do GPCEMai vêm ocorrendo desde março de 2013 nas dependências da UFMS. 
Em investigação sobre trabalhos colaborativos, Ferreira (2013, p. 152) destaca que "[...] cada indivíduo participa da maioria das decisões: escolher a meta, definir as estratégias, definir as tarefas, avaliar o resultado. E o faz consciente de que é algo realmente importante para ele, algo que tanto beneficia o grupo como um todo, quanto a ele diretamente. [...]". Desse modo, todos os indivíduos envolvem-se com o mesmo compromisso e esforços para favorecer um objetivo em comum, proporcionando transformações positivas no ensino e na aprendizagem.

Num trabalho colaborativo, a participação do grupo ocorre de maneira ativa como fonte de aprendizagem. $O$ espaço oportuniza reflexões e troca de experiências, permitindo que o professor questione, explore e aprenda com os seus saberes e com os saberes dos demais colaboradores (FERREIRA, 2013).

Tendo em vista estes princípios, é por meio da troca de experiências que o professor torna-se autor do seu próprio desenvolvimento, levantando discussão e novas propostas para solucionar os problemas oriundos de sua prática pedagógica que, quando discutidos/refletidos coletivamente, podem oportunizar a consciência de determinadas ações.

A participação em grupos colaborativos deve ocorrer de maneira espontânea, como afirma Nacarato (2013, p. 27): “[...] Os professores participam desses grupos voluntariamente, única e exclusivamente pelo desejo de aprender e compartilhar prática. Eles não estão em busca de atender a agendas externas às escola que os obriguem a participar de projetos de formação." Deste modo, o trabalho em grupo apresenta potencial para ampliar o conhecimento pela sinceridade e compromisso dos integrantes em buscar a construção conjunta no desenvolvimento de sua autonomia e melhoria da prática.

Nacarato (2013, p. 27) considera, ainda, que os “[...] grupos atendem aos anseios dos professores, porque estes têm voz e são ouvidos. O que eles têm a dizer interessa a toda a comunidade, que compartilha das mesmas necessidades, das mesmas angústias e das mesmas problemáticas nos cotidianos escolares." Sendo assim, o espaço coletivo oportuniza o falar sobre as práticas, incertezas e problemas enfrentados em sala de aula, sem a preocupação de críticas negativas e exposição; os professores sentem-se seguros e livres para expressar seus sentimentos.

Um grupo com características colaborativas proporciona aos professores a troca de experiências e a problematização da prática docente, rompendo com o isolamento e tirando-os da zona de conforto, abrindo possibilidades de reflexão e autonomia num contexto grupal (CIRÍACO; MORELATTI, 2016). Nacarato et al. (2013, p. 67) esclarecem que "[...] é a partir da problematização da prática que o professor passa a refletir e produzir significados para os acontecimentos que vivencia [...]". Defendem, ainda, que "[...] os contextos que privilegiam a problematização, análise e reflexão da prática pedagógica são potencializadores do desenvolvimento profissional do professor."

Um ponto marcante dentre as características dos grupos colaborativos é a voluntariedade, identidade e espontaneidade dos integrantes, assim como pontuam Nacarato et al. (2013, p. 199): a “[...] participação no grupo é voluntária, no sentido de que cada membro deseja fazer parte de um determinado grupo, com predisposição para contribuir e aprender com seus pares, a partir de um interesse comum o que imprime 
ao grupo uma identidade." Essa identidade, embora constituída por objetivos comuns, não perde o interesse individual de cada integrante se desenvolver profissionalmente e ampliar seus conhecimentos.

De acordo com Rodrigues et al. (2016), a divisão de responsabilidades é uma importante característica do trabalho colaborativo, favorece o diálogo e possibilita que todos possam participar ativamente do processo, oferecendo condições para o fortalecimento do grupo. Damiani (2008), ao discorrer sobre as potencialidades do trabalho colaborativo, considera que este possui potencial de ampliar o conhecimento e modificar a maneira de pensar o desenvolvimento pedagógico, proporcionando sucesso na solução de problemas educacionais.

Destacando a investigação da prática associada à participação em grupo colaborativo, Fiorentini e Crecci (2012, p. 71-72) destacam que

[...] os professores que possuem uma postura de estudo e buscam parceiros para analisar e discutir suas práticas pedagógicas apresentam fortes indícios de que desejam uma participação mais ativa, contínua e autônoma, sendo protagonistas dos processos de mudança curricular a partir da escola e de seu processo de desenvolvimento profissional; assim, podem elencar prioridades a serem estudadas, compartilhando e refletindo sobre a própria prática de ensinar e aprender matemática na escola.

As questões evidenciadas pelos autores supracitados são elementos constitutivos da dinâmica colaborativa instituída pelo grupo objeto de estudos da investigação apresentada neste artigo. Desse modo, temos presenciado o envolvimento dos integrantes em processos de leitura e discussão, como também em análise crítica de episódios de aulas de Matemática nos anos inicias do Ensino Fundamental, o que, sem dúvida, coloca em xeque o caminho promissor da colaboração neste contexto em que estamos a trabalhar.

Nacarato $(2013$, p. 30$)$ defende que "[...] um dos grandes desafios postos às professoras que atuam nos anos iniciais diz respeito à formação específica para ensinar os diferentes componentes curriculares." Na visão da autora, ainda é possível destacar que a dificuldade encontrada, principalmente por egressos do curso de Pedagogia, está associada a uma formação generalista, a qual se estende a vários campos. Embora contemple algumas disciplinas específicas, a carga horaria é reduzida, não proporcionando suporte adequado à formação conceitual exigida ao ingressarem na prática profissional (NACARATO, 2013).

Ao analisarmos os entraves existentes na formação inicial de professores no ensino da Matemática escolar, podemos inferir que é preciso uma nova postura e vertente de formação, para além dos bancos universitários, que promova, de fato, o reconhecimento das limitações didáticas e conceituais no sentido de colocar o professor em movimento de aprendizagem e melhoria de suas ações.

Imbernón (2011, p. 12) esclarece que, diante da nova forma de educar que a educação assume, faz-se necessário "[...] uma redefinição importante da profissão docente e que se assumam novas competências profissionais no quadro de um conhecimento pedagógico, científico e cultural revisto." Em outras palavras, a nova era requer um profissional da educação diferente, ou seja, um professor reflexivo. Para tanto, a formação 
desses professores deve exceder as características de mera atualização e promover a participação e a reflexão no contexto de grupo, de modo que venha a subsidiar uma educação transformadora e democrática aos cidadãos.

Sendo assim, é imprescindível que o professor tenha uma formação que o possibilite, mais do que ensinar, que possa refletir sobre suas práticas pedagógicas e sobre o seu próprio processo de ensino em investigação por ferramentas cabíveis para atender às necessidades dos alunos (PAVANELLO, 2009).

Com base nestas considerações, a formação contínua tem se revelado uma ferramenta promissora no processo de conscientização de processos de transformação no ensino. Isso porque ela abarca as necessidades peculiares do professor, articulando o conhecimento específico e didático ao tentar desconstruir práticas equivocadas, apoiando-se em novos saberes docentes ao promover espaços coletivos de reflexão sobre as ações adotadas para o ensino de determinados conteúdos matemáticos.

\section{METODOLOGIA}

A metodologia inscreve-se no campo de pesquisa qualitativa (BOGDAN; BIKLEN, 1994), de caráter descritivo-analítico, resultado do contato direto dos pesquisadores com o ambiente natural de coleta de dados, haja vista a participação direta da primeira autora no espaço em que o trabalho ocorreu, ou seja, esteve inserida diretamente como integrante de um grupo com características colaborativas de Educação Matemática.

Conforme já destacado na seção introdutória, a coleta de dados foi desenvolvida no contexto das sessões do GPCEMai-UFMS, em que as características da formação envolveram processos de colaboração e compartilhamento das experiências e práticas profissionais de suas integrantes. No caso específico deste estudo, as ações centraram-se no intuito de responder o objetivo de compreender em que medida a prática de compartilhar experiências no contexto de um grupo colaborativo, com professoras que ensinam Matemática, contribui para o processo reflexivo do fazer docente nos anos iniciais do Ensino Fundamental.

Para atingir o objetivo referido, adotaram-se técnicas e esforços no percurso metodológico que envolveu os seguintes passos:

19) Início das sessões do GPCEMai com o foco no trabalho com a Geometria: com o início do ano letivo, as reuniões do grupo foram retomadas e ocorreu a negociação dos interesses de estudo, bem como das necessidades formativas. No direcionamento das primeiras sessões já destacamos que a Geometria seria o foco, e as docentes, professoras da rede municipal e estadual do município de Naviraí, interior do Estado de Mato Grosso do Sul, atuantes em turmas de 1으 ao 5으 ano do Ensino Fundamental, se integrariam às ações coletivas.

No ano de 2017, o grupo teve a assiduidade de 14 sujeitos, sendo 5 professoras dos anos iniciais, 2 coordenadoras pedagógicas, 4 acadêmicas de Licenciatura em Pedagogia, 2 estudantes de Mestrado acadêmico do Programa de Pós-Graduação em Ensino 
e Processos Formativos da Unesp/Ilha Solteira ${ }^{4}$ e 1 professor/formador da UFMS. Os encontros de estudo em Geometria iniciaram-se em meados de março e vêm se desenvolvendo mensalmente, com o intuito de estudar, discutir temáticas e planejar aulas com conteúdos específicos da Matemática escolar, como também compartilhar e discutir as práticas realizadas pelas professoras em sala de aula.

2) Observação das práticas de compartilhamento e da dinâmica do grupo: o contato direto com o espaço natural da investigação proporcionou realizarmos observação sistemática com os olhares voltados a colher o maior número de situações que pudessem responder aos aspectos centrais da pesquisa, como o tipo de registro da prática adotado pelas professoras, a interação e a participação das colaboradoras no que diz respeito às discussões acerca das temáticas estudadas, o sentimento demonstrado ao compartilhar as práticas com o grupo, se as intervenções pedagógicas realizadas pelo professor-formador abarcam as fragilidades demonstradas pelo grupo, entre outros aspectos imprescindíveis para a construção da investigação.

Lüdke e André (1986, p. 26) consideram que

[...] a observação possibilita um contato pessoal e estreito do pesquisador com o fenômeno pesquisado, o que apresenta uma série de vantagens. Em primeiro lugar, a experiência direta é sem dúvida o melhor teste de verificação da ocorrência de um determinado fenômeno. "Ver para crer", diz o ditado popular.

As autoras ainda salientam que a observação direta estreita a relação do observador com o objeto de pesquisa, proporcionando a compreensão e a interpretação do fato investigado. Neste sentido, não medimos esforços para a verificação da realidade pesquisada, realizando anotações de forma a registrar com seriedade as observações feitas a cada reunião, sempre pautando em responder os indicadores da pesquisa bem como os aspectos que regem o estudo.

As reuniões observadas ocorreram por meio de uma dinâmica em que, primeiramente, tivemos estudos teóricos que versaram sobre temáticas específicas da Educação Matemática (ensino de Geometria), os quais buscavam aproximar-se das necessidades que são comuns ao grupo, além de promover discussões sobre práticas e metodologias pedagógicas que visam a potencializar as aprendizagens e o desenvolvimento profissional dos participantes para a melhoria do aprendizado dos alunos.

Em seguida, ocorriam momentos de planejamento das aulas, apoiados nas bases teóricas discutidas, para validar as propostas. Nas reuniões subsequentes, o grupo apresentava a aula ministrada por meio do registro, que poderia ser videogravação, narrativa escrita e/ou fotografia e, assim, retomava o primeiro ponto (estudos teóricos) em um movimento cíclico.

3) Elaboração do roteiro de entrevista: com questões articuladas com as situações verificadas durante as observações. De acordo com Severino (2007), a entrevista é uma técnica utilizada para o pesquisador conhecer o significado que o entrevistado dá aos fenômenos e eventos de sua vida cotidiana, utilizando seus próprios termos.

Coorientadas pelo segundo autor deste artigo e que desenvolveram, assim como nós, suas pesquisas de Mestrado no contexto da colaboração deste mesmo grupo. 
Foram propostas um total de 15 questões, envolvendo pontos relacionados com o percurso vivenciado no grupo colaborativo, o critério para a escolha da forma de registro, a participação nas reuniões, as possibilidades de reflexão a partir da interação entre as integrantes, as atividades realizadas para o ensino da Geometria e as contribuições das práticas compartilhadas.

Bogdan e Biklen (1994, p. 134) esclarecem que "[...] a entrevista é utilizada para recolher dados descritivos na linguagem do próprio sujeito, permitindo ao investigador desenvolver intuitivamente uma ideia sobre a maneira como os sujeitos interpretam aspectos do mundo". Para melhor acuidade no momento da entrevista, utilizamos como instrumento para o seu registro a gravação direta, no sentido de captarmos todas as expressões orais dos entrevistados.

40) Análise de dados: ao fim da investigação realizamos as sínteses das observações e as transcrições das entrevistas, possibilitando realizar análise dos dados para compreendermos as situações investigadas.

Para Lüdke e André (1986, p. 45), "Analisar os dados qualitativos significa 'trabaIhar' todo o material obtido durante a pesquisa, ou seja, os relatos de observação, as transcrições de entrevista, as análises de documentos e as demais informações disponíveis." Buscamos realizar o cruzamento dos dados e das informações coletadas durante a investigação.

A análise de dados ocorreu na perspectiva de compreender três aspectos do registro das professoras: a) descrição da opção por determinado tipo de registro; b) natureza das atividades matemáticas propostas e; c) apresentação do desenvolvimento da aula, de maneira a compreender criticamente o sentido oculto das informações coletadas.

\section{Caracterização das professoras}

Quanto às professoras participantes da pesquisa, utilizamos o critério de maior assiduidade no grupo e o fato de estarem em diferentes fases da carreira, sendo uma iniciante e a outra experiente, às quais, neste artigo, nos referiremos como professora Simetria e professora Aresta.

Simetria possui duas graduações, sendo ambas no campo da Licenciatura: Letras e Pedagogia. Possui especialização em Psicopedagogia e atua há, aproximadamente, quatro anos na rede pública de ensino. No momento desta pesquisa a professora trabalhava em uma turma de 4ㅇ ano do Ensino Fundamental em uma escola estadual.

Quanto à formação da professora Aresta, possui Licenciatura em Pedagogia e faz 17 anos que está em atividade profissional. Atualmente, leciona para o 3o ano do Ensino Fundamental na rede pública de ensino municipal.

\section{DIVIDIR PARA SOMAR PRÁTICAS COMPARTILHADAS: COMPREENDENDO A DINÂMICA DAS REUNIÕES}

Iniciamos as reuniões do grupo contando com 13 professoras que ensinam Matemática nos anos iniciais do Ensino Fundamental. Primeiramente, foi explicada a proposta dos encontros, em que a dinâmica a ser instituída seria a colaborativa, com base na interação das integrantes, estudos e discussões de textos, planejamento e desenvol- 
vimento da prática em sala de aula, como também compartilhamento do registro e reflexões sobre as ações. Feito isso, solicitamos a colaboração para que cada participante registrasse suas aulas para compartilhar. Tais registros poderiam ser em qualquer uma das três formas: a) fotográfica; b) escrita narrativa; e c) videogravação.

De início, as professoras mostraram-se receosas ao saber que as reuniões seriam gravadas com a finalidade de pesquisa, e que a dinâmica ocorreria com base nos registros e compartilhamento das aulas ministradas por elas. Destacamos, porém, já no primeiro encontro, alguns aspectos característicos do espaço colaborativo que, para Fiorentini (2003), baseia-se na voluntariedade, identidade e espontaneidade, liderança compartilhada ou corresponsabilidade e apoio e respeito mútuo. Reforçando ainda, a fidelidade e ética do trabalho colaborativo diante os dados e discussões apresentados no grupo (CIRÍACO; MORELATTI, 2016).

Nos primeiros encontros essas características não se mostraram totalmente presentes, porém foram construídas a partir da interação entre as integrantes, da troca de experiências e do diálogo entre os pares a cada encontro.

Durante o processo desta investigação, as reuniões ocorreram pautadas em dois eixos. O primeiro refere-se ao estudo teórico de temáticas centradas no ensino da Geometria, utilizando referencial teórico da Educação Matemática. Embora haja a participação de todos os integrantes no estudo teórico, contamos com a colaboração de uma dupla da equipe para fomentar as discussões. A dupla, em geral, é constituída por uma professora e uma acadêmica do curso de Pedagogia. Além disso, no decorrer do estudo ocorrem intervenções mediadas pelo segundo autor deste artigo, e comentadas pelos demais, o que tem contribuído para novas possibilidades/recursos para o ensino. As interações decorrentes da prática coletiva de estudo deram-se de maneira dialógica, proporcionando discussões e reflexões críticas.

Observamos que as discussões e reflexões dos textos teóricos ampliaram em propostas de atividades para serem trabalhadas com os alunos em sala de aula, contribuindo para o planejamento das futuras aulas das professoras, pois, ao realizarem o planejamento, empregam propostas discutidas no contexto colaborativo.

O segundo eixo incide quando as professoras compartilham o registro de suas práticas em sala de aula por meio de videogravação, narrativa escrita e/ou fotografia. Esse momento ocorre a partir de uma apresentação ao grupo sobre como a aula se desenvolveu, seguido da contribuição dos demais integrantes ao analisarem a aula apontando pontos positivos e o que poderia ser melhorado em outras intervenções em relação ao mesmo assunto/conteúdo.

Observamos que, embora ainda tímidas, todas as professoras compartilharam os seus registros durante os encontros, o que provocou boas discussões e reflexões acerca da prática desenvolvida no campo da Geometria nos anos iniciais do Ensino Fundamental. Notamos que a forma de registro mais explorada no grupo foi a fotografia, ficando, assim, a narrativa escrita e a videogravação em segunda opção. Independente do recurso adotado para registrar a prática, as docentes não deixaram de narrar as suas aulas e apresentar as características do trabalho pedagógico adotado para o direcionamento da aula, enunciando, assim, o que fizeram ao apresentar as fotografias das tarefas compartilhadas no grupo.

Durante os encontros foi notável que o movimento gerado pela ação do compartilhar impulsionou o processo de investigação e reflexão, haja vista que as professoras mencionam que pararam para analisar suas práticas e que este retomar permitiu um 
olhar mais atencioso voltado às suas ações, dado esse que corrobora os dizeres de Fontana e Fávero (2013), quando os autores destacam a relevância da necessidade de o professor refletir sobre a ação, reconstruindo e analisando sua prática com um olhar mais cuidadoso, de maneira a perceber como o seu trabalho foi desenvolvido e onde pode melhorar para alcançar os objetivos propostos, elementos estes que temos explorado com as docentes colaboradoras deste estudo.

Ao compartilhar experiências vivenciadas no dia a dia da sala de aula, o grupo abriu espaço para reflexões permanentes das práticas profissionais que vinham desenvolvendo, muitas vezes de forma isolada, em seus postos de trabalho. Com as discussões durante os encontros, abre-se uma agenda de assuntos que revelam problemas e dificuldades do processo de ensino e aprendizagem matemática, como também um leque de possibilidades de intervenção no sentido de contribuir com o desenvolvimento das aulas e do aprender/ensinar Geometria nos primeiros anos. Observamos, por diversas vezes, alguns questionamentos levantados pelas professoras, buscando, por meio do grupo, compreender suas práticas de modo a modificá-las com novas possibilidades para trabalhar com seus alunos.

\section{Entre flashes, cliques e rec's: o registro das aulas de Matemática pelas professoras}

\section{O registro reflexivo da aula no espaço de formação compartilhada do/no grupo}

Os registros de videogravação de Simetria e de fotografia de Aresta compartilhados, apresentam características sobre o ensino da Geometria, nos quais o objetivo da aula estava relacionado com a compreensão das características dos sólidos geométricos.

O Quadro 1, a seguir, apresenta alguns aspectos do cenário da aula de Simetria.

Quadro 1 - Descrição dos aspectos do vídeo de Simetria compartilhado no grupo ${ }^{5}$

\begin{tabular}{|c|c|c|c|}
\hline $\begin{array}{l}\text { INTRODUÇÃO DO } \\
\text { CONTEÚDO }\end{array}$ & $\begin{array}{c}\text { RECURSO/MATERIAIS } \\
\text { UTILIZADOS }\end{array}$ & $\begin{array}{l}\text { DESENVOLVIMENTO/ } \\
\text { DINÂMICA DA AULA }\end{array}$ & AVALIAÇÃO \\
\hline $\begin{array}{l}\text { Abordagem oral, } \\
\text { apresentando } \\
\text { por meio dos } \\
\text { blocos lógicos } \\
\text { representações de } \\
\text { formas geométricas. } \\
\text { Utilização de objetos } \\
\text { do cotidiano para } \\
\text { relacionar com os } \\
\text { sólidos geométricos } \\
\text { e suas planificações. }\end{array}$ & $\begin{array}{l}\text { a) Blocos lógicos; } \\
\text { b) Objetos do } \\
\text { cotidiano. Ex.: caixas } \\
\text { de remédio, caixas de } \\
\text { sapato, embalagem } \\
\text { de desodorante, entre } \\
\text { outros. }\end{array}$ & $\begin{array}{l}\text { A professora nomeou os principais } \\
\text { sólidos e suas características, e } \\
\text { apresentou as planificações dos } \\
\text { sólidos geométricos relacionando } \\
\text { com objetos do cotidiano, } \\
\text { questionando e deixando os alunos } \\
\text { participarem. Após foram realizadas } \\
\text { atividades em conformidade com } \\
\text { o livro didático, relacionando os } \\
\text { sólidos com as suas planificações. Em } \\
\text { seguida, houve ainda a identificação } \\
\text { de objetos do cotidiano com sólidos. } \\
\text { A professora também solicitou } \\
\text { que realizassem a montagem das } \\
\text { planificações dos sólidos como tarefa } \\
\text { a ser feita em casa. }\end{array}$ & Não houve. \\
\hline
\end{tabular}

Fonte: Os autores, 2017. 
Ao compartilhar essa experiência no espaço colaborativo, Simetria revelou que a filmagem de sua aula possibilitou uma reflexão crítica sobre suas práticas: "o vídeo faz refletir mais sobre a prática, a escrita; é uma reflexão minha. O vídeo mostra as ações das crianças, oportuniza mais momentos de reflexão". Ainda discursou que percebeu que pode e deve explorar mais essa forma de registro de sua atuação, mas que ainda precisa sair da zona de conforto.

Por meio do vídeo observamos que Simetria empenhou-se em desenvolver a atividade proposta do planejamento realizado junto ao grupo, pois essa foi a primeira aula de Geometria ministrada no ano letivo por esta professora, uma vez que foi no ambiente da colaboração que ela encontrou significado para desenvolver este tipo de trabalho. Durante uma das reuniões com o grupo colaborativo, ela revelou que pensou até em desistir de assumir a turma do 4 o ano do Ensino Fundamental, por perceber, quando do momento de analisar o referencial curricular, que a Geometria estava presente e que iria ter de desenvolver propostas das quais nem ela tinha conhecimento.

Durante o episódio de aula assistido, analisado e comentado pelo grupo, ${ }^{6}$ foi possível notar a incorporação de uma metodologia de aula com características mais exploratórias, em que a docente procurou relacionar o conteúdo com objetos concretos do cotidiano dos alunos, deixando-os se envolverem mais ativamente na tarefa proposta, elementos estes discutidos no grupo como sendo essenciais para a compreensão dos objetos geométricos. A cena a seguir exemplifica um momento da aula em que uma caixa de sapato é utilizada como referência para contextualizar as planificações.

\section{Figura 1 - Cena da aula de Simetria}

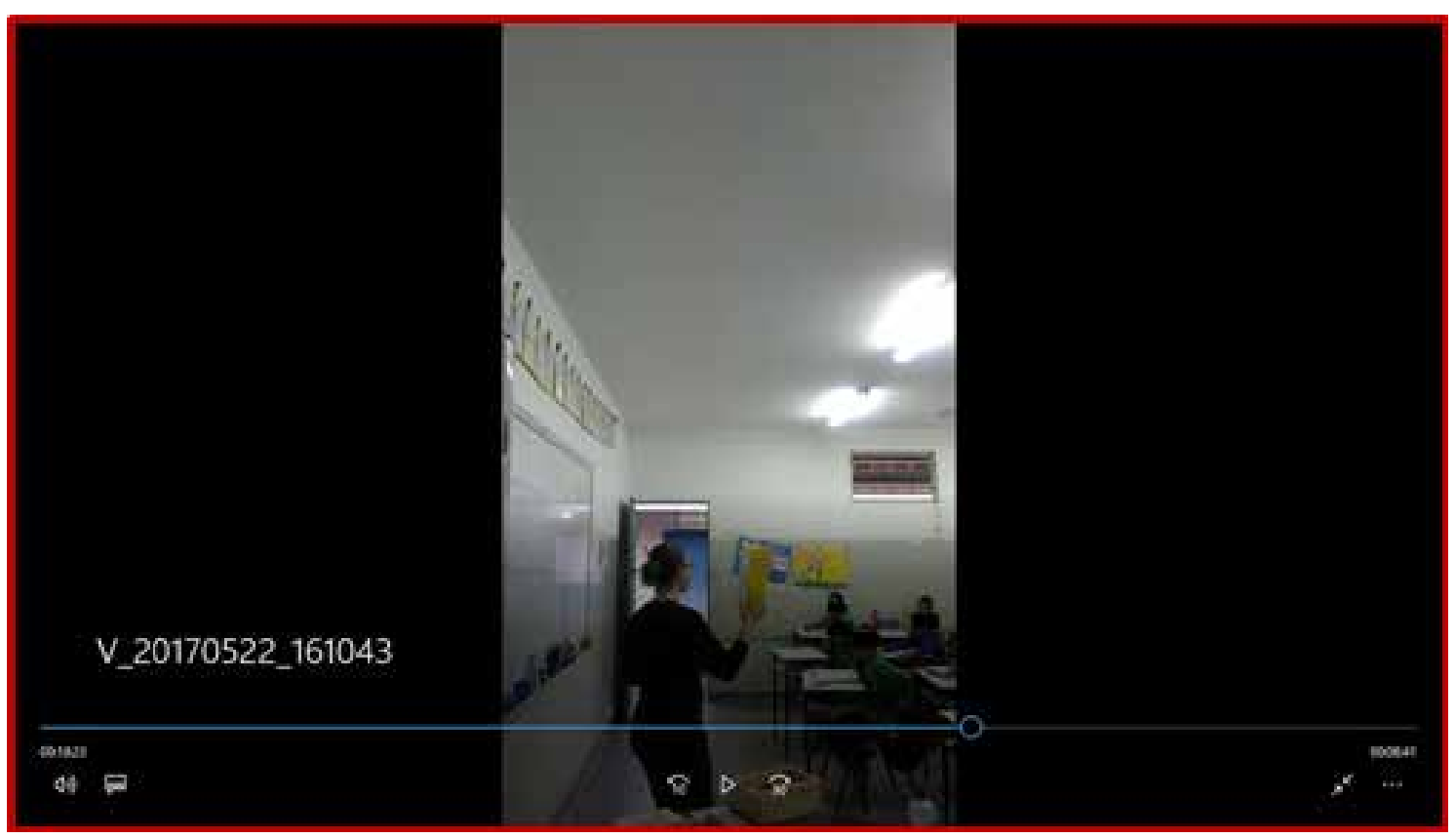

Fonte: Acervo de videogravação da professora, 2017.

Assume-se, neste artigo, a escrita narrativa em que os autores incorporam o discurso do grupo ao interpretá-lo e redigirem afirmações baseadas nas interações entre as professoras durante as reuniões. Assim, não se torna preciso, necessariamente, trazer excertos destes momentos para o texto. 
Percebemos, na reunião em que Simetria trouxe sua aula para análise, que esta utilizou algumas contribuições que foram abordadas no grupo como aporte teórico-metodológico. Para abordar o conteúdo sobre figuras e sólidos geométricos, a professora iniciou explicitando que a Matemática é formada por vários eixos e não se limita em "números e operações", mas abrange um conjunto de blocos de conteúdos que são primordiais para o desenvolvimento de cada indivíduo, dentre eles a Geometria.

Em sequência, exibiu à turma a representação de um quadrado por meio de blocos lógicos e indagou: "Que figura é esta?" "Quais as características que possui?". A turma assim respondeu: "é um quadrado por apresentar os quatro lados iguais".

Ao questionar as características da figura aos alunos, Simetria proporcionou estímulos para o pensar geométrico. Broitman e Itzcovich (2006), em seus estudos, defendem que o conhecimento geométrico precisa ser sistematizado para promover a apropriação dos conceitos e das propriedades de figuras e dos sólidos. Destacam a importância de proporcionar condições para que os alunos possam pensar a Geometria de uma maneira a produzir saber e conhecimento, o que pode ser proposto a partir de um diálogo nas aulas de Matemática, tal como feito pela docente.

Simetria apresentou a representação de um triângulo, fazendo os mesmos questionamentos da figura anterior. Inclinando a forma, em outro arranjo espacial, indagou: "Mas se eu colocar nesta posição, continua sendo um triângulo?" Neste momento, abriu espaço para discutirem as diferentes posições em que uma figura pode estar disposta e, ainda, a medida de seus lados, o que faz do triângulo, por exemplo, ser equilátero, escaleno ou isósceles, permitindo uma melhor visualização destes conceitos.

Além disso, possibilitou, no diálogo com a turma do 4 을 ano, reflexões sobre a associação das figuras com a cor e espessura, destacando que o que as definem são as características peculiares e atributos de cada figura. Tal abordagem em sala de aula trouxe o entendimento ao grupo das discussões levantadas pela leitura do texto de Ciríaco, Morelatti e Ponte (2016).

Em seu vocabulário, a professora utilizou os termos convencionais para tratar o conjunto de propriedades das figuras, por exemplo, a quantidade de arestas, de vértices, entre outros termos específicos. A importância de um vocabulário rico e a utilização de termos específicos, foram pautadas no decorrer das reuniões como sendo importantes para que os alunos se apropriem dos conceitos geométricos.

Após o compartilhamento do registro, algumas observações e contribuições foram levantadas em relação aos aspectos do modo como a aula transcorreu quanto ao processo de planificação e posterior representação dos sólidos geométricos por meio das embalagens (caixas).

Inicialmente o grupo colocou em xeque a explicação dada pela professora ao afirmar que a embalagem era um sólido geométrico. $O$ discurso exerce influência no modo como as crianças passam a classificar em Geometria. Neste sentido, as demais professoras chamaram a atenção para uma questão já debatida anteriormente no ambiente de colaboração: o fato de que a embalagem em si não é um sólido, mas, sim, uma representação da superfície do sólido. A partir da mediação do segundo autor deste ar- 
tigo, fora explicitado, ainda, que é preciso ter este cuidado durante o desenvolvimento do pensamento geométrico nos anos inicias, uma vez que os alunos podem vir a compreender equivocadamente o conceito de sólidos geométricos.

Simetria, a partir da interação e da contribuição das demais integrantes, refletiu que a experimentação auxilia na criação de imagens mentais e que essa tarefa pode, ainda, exercer um papel importante na abstração e na formalização dos conceitos, desde que articulada com o contexto de seus alunos, por isso apontou a relevância de expor seu vídeo ao grupo.

Apesar da explicação inadequada sobre as embalagens serem sólidos e não representação destes, a professora teve uma prática interessante em momentos posteriores a este instante, pois durante a aula foi possível verificar que explorou com seus alunos o reconhecimento de diferenças e semelhanças entre as caixas, questão fundamental para este tipo de trabalho. Ao fazer isso, Simetria oportunizou que seus alunos reconhecessem a identificação de características dos atributos definidores de faces, vértices e arestas e, com isso, fora nomeando os sólidos geométricos com a turma.

Já a professora Aresta, ao compartilhar o tipo de registro de aula que adotou para desenvolver a atividade proposta (o fotográfico), mencionou que este the proporcionou refletir e analisar as ações junto as crianças: "foi por meio do registro que refleti sobre minhas ações; valeu a pena! Põe a gente para pensar, buscar". Com base em sua declaração, foi perceptível, durante a entrevista, que o registro da aula proporciona ao professor refletir sobre suas ações, e encoraja-o a pensar e buscar novos caminhos para solucionar os problemas enfrentados.

O Quadro 2, a seguir, apresenta alguns aspectos do cenário da aula de Aresta.

Quadro 2 - Descrição dos aspectos da aula fotografada por Aresta compartilhada no grupo

\begin{tabular}{|c|c|c|c|}
\hline $\begin{array}{l}\text { INTRODUCÃO DO } \\
\text { CONTEÚDO }\end{array}$ & $\begin{array}{l}\text { RECURSO/ } \\
\text { MATERIAL } \\
\text { UTILIZADO }\end{array}$ & $\begin{array}{l}\text { DESENVOLVIMENTO/ } \\
\text { DINÂMICA DA AULA }\end{array}$ & AVALIAÇÃO \\
\hline $\begin{array}{l}\text { Roda de conversa, } \\
\text { a fim de perceber } \\
\text { os conhecimentos } \\
\text { prévios dos alunos. } \\
\text { Abordagem } \\
\text { oral sobre as } \\
\text { figuras e sólidos } \\
\text { geométricos e seus } \\
\text { atributos. } \\
\text { Utilização } \\
\text { de materiais } \\
\text { recicláveis } \\
\text { representando } \\
\text { os sólidos } \\
\text { geométricos } \\
\text { para montagem } \\
\text { de objetos/ } \\
\text { brinquedos livre. } \\
\text { Brincadeira "rola } \\
\text { ou não rola". }\end{array}$ & $\begin{array}{l}\text { a) Blocos } \\
\text { lógicos; } \\
\text { b) Objetos } \\
\text { do cotidiano. } \\
\text { Ex.: caixas, } \\
\text { chapéu de } \\
\text { aniversário, } \\
\text { lata de leite, } \\
\text { cone de PVC, } \\
\text { entre outros. }\end{array}$ & $\begin{array}{l}\text { A professora iniciou a discussão sobre os sólidos } \\
\text { geométricos indagando o que eles entendiam } \\
\text { sobre sólidos geométricos. Qual a diferença entre } \\
\text { eles? Quais são os atributos que distingue uns dos } \\
\text { outros? Onde podemos perceber representações de } \\
\text { sólidos? Em seguida, solicitou uma atividade para } \\
\text { fazer em casa com a ajuda da família, orientando- } \\
\text { os a produzirem, por meio de materiais recicláveis } \\
\text { representando os sólidos geométricos, objetos ou } \\
\text { brinquedos de acordo com seus critérios. Em outra } \\
\text { aula, a professora retomou a discussão utilizando } \\
\text { os objetos construído pelos alunos. Deixou os } \\
\text { alunos falar sobre a experiência e explicarem cada } \\
\text { representação geométrica que foi utilizada e o que } \\
\text { acharam da atividade. Em seguida, a professora } \\
\text { orientou-os a saírem para o pátio e realizarem uma } \\
\text { brincadeira conhecida como "rola ou não rola". } \\
\text { Primeiramente a professora explicou a brincadeira } \\
\text { e deixou os alunos explorar e se envolverem na } \\
\text { brincadeira. A cada resposta dos alunos sobre } \\
\text { os objetos que rolam ou não rolam, a professora } \\
\text { mediava a aprendizagem esclarecendo as dúvidas. }\end{array}$ & Não houve. \\
\hline
\end{tabular}

Fonte: Os autores, 2017. 
Por meio dos registros e das narrativas orais de Aresta ao apresentar sua aula no grupo, percebemos o desenvolvimento de estratégias significativas nas tarefas propostas junto a turma no ensino da Geometria, posto que utilizou materiais concretos e recorreu às brincadeiras para contextualizar os sólidos geométricos e suas características, como podemos ver na Figura a seguir.

Figura 2 - Aula de Aresta

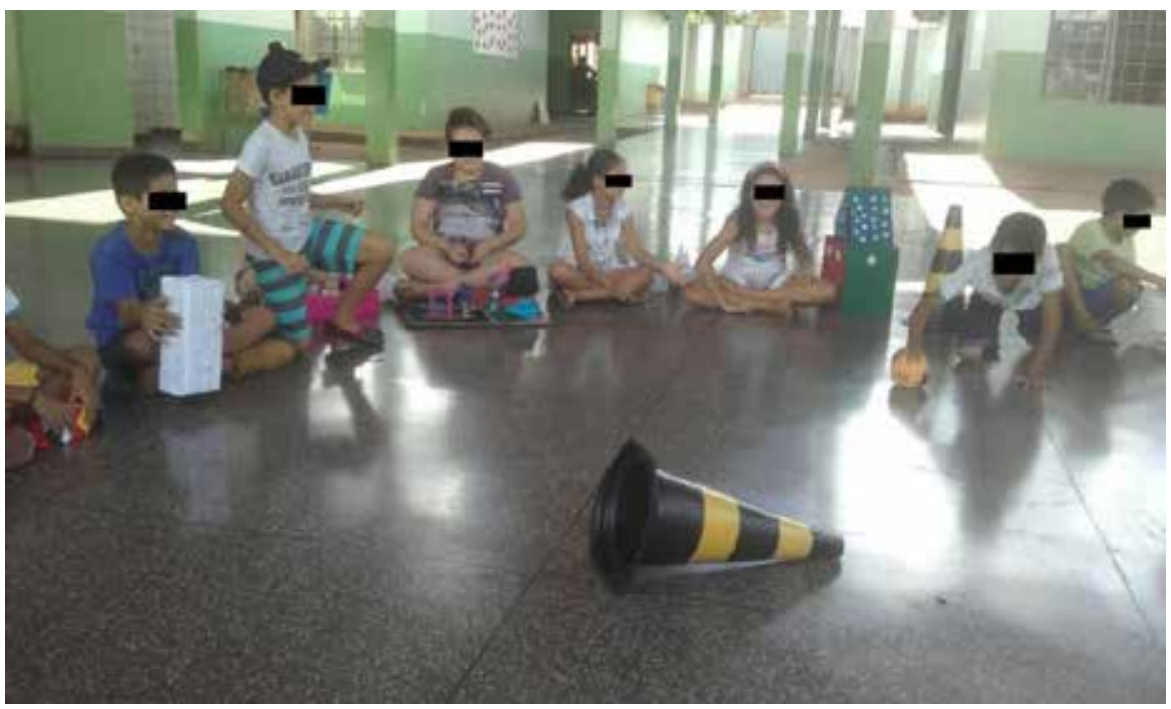

Fonte: Acervo fotográfico da professora Aresta, 2017.

Ao compartilhar essa experiência, Aresta revelou que a prática de fotografar a sua aula permitiu retomar processos adotados para o direcionamento da tarefa, e ainda vivenciar o que aconteceu, e que, ao rememorar o percurso, quando do momento da seleção das fotos para apresentação no grupo, conseguiu identificar alguns equívocos cometidos e, assim, buscar melhorar ao compartilhar e explicar na reunião com as demais professoras dos anos iniciais. Também pode perceber os pontos positivos, como a interação e a disposição dos alunos ao participarem das atividades demostrando alegria e prazer ao se envolverem na proposta. Enfim, Aresta reconheceu que é possível ensinar e aprender de forma exploratória brincando.

\section{O que dizem as professoras sobre seus registros e as contribuições do grupo colaborativo à docência em Matemática?}

Tendo em vista que a opção pela adoção do tipo de registro da aula ficou a cargo das professoras com base nas três possibilidades levantadas pelo grupo (narrativa escrita, fotografias e/ou videogravação), questionamos Simetria e Aresta sobre qual foi o sentimento ao registrar e compartilhar:

[...] a gente sente-se um pouco inseguro, porque você está abrindo a porta de sua sala que normalmente fica em quatro paredes, você e seus alunos e aí você tá assim, abrindo seu espaço de trabalho, a sua prática para outros profissionais. Essa insegurança eu acho que é normal, mas quando eu vi os outros profissionais fazendo [...]. [...] e por se tratar de um grupo pequeno e que você tem dois lados, dois tipos de participantes, que são os professores e os acadêmicos, a gente acaba trocando a questão da angústia da sala de aula com as angústias do banco acadêmico, da academia (SIMETRIA). 
Eu acho muito bom porque, às vezes, nós ficamos um tempo fora da sala de aula enquanto aluno e nós temos muita coisa ainda para aprender, principalmente com o que está chegando agora, porque as coisas também mudam o jeito de trabalhar, as técnicas [...] e aflora na gente essa ideia de buscar também; então, foi uma prática muito boa esse compartilhamento, ouvir outras colegas de trabalho, também os anseios, as novidades, o que estão fazendo na sala e que deu certo, então, para mim foi muito bom (ARESTA).

A fala de Simetria demonstra que a insegurança inicial em registrar e compartiIhar sua prática foi, gradativamente, sendo substituída pela confiança ao presenciar os registros compartilhados pelas demais colegas e, também, pelas contribuições das acadêmicas de Pedagogia participantes do grupo colaborativo. Neste processo, o professor que ensina Matemática nos anos iniciais não se sente mais sozinho em sua trajetória de ensino. Temos aqui um exemplo do quanto o compartilhamento das experiências implica o sentimento de partilha, do estar junto, de pertencer a um grupo que visa a contribuir para o desenvolvimento profissional nas aulas. A enunciação de Aresta demonstra motivação em buscar novas ideias e técnicas impulsionadas pela interação no espaço de colaboração, em que os anseios e medos foram desaparecendo na medida em que percebeu que todas estavam no "mesmo barco", ou seja, na condição de protagonistas de seu processo de ensino e aprendizagem sobre as práticas do aprender a ensinar a partir das recomendações da literatura especializada na temática das aulas que ministraram. Entendemos que, em ambos os casos, as falas exprimem resultados das características colaborativas que o grupo atribui por proporcionar um espaço estimulador para o diálogo "de" e "sobre" Matemática.

Dando continuidade à entrevista, perguntamos qual é o sentimento expresso ao retomar a prática realizada em sala de aula por meio do registro:

A gente se sente um pouco exposto e coloca em tono [coloca em evidência] as nossas fragilidades ali, a questão da postura na sala de aula, o andar pelo espaço da sala, eu percebi que fico muito na frente, muito ali naquele meu espaço do professor (...). Continuar fazendo mais prática, trabalhar mais com o concreto, porque essa aula que, de certa forma foi filmada, quando eu vi o vídeo, eu vi o entusiasmo deles [referindo-se às crianças], a participação deles, então, esse concreto, por mais que fala-se tanto, desde a universidade a gente ouve falar, ainda é muito forte a questão do tradicionalismo: livro, caderno, quadro; a gente fica muito nisso! Então, fugir um pouco do livro e trabalhar o concreto, mão na obra mesmo (SIMETRIA).

Os erros, a gente vê coisas assim quando começa a descrever, igual no meu caso, eu fiz a parte escrita e a parte fotográfica, você está fazendo ali, aí você fala: "nossa eu podia ter feito isso aqui diferente!" Eu acredito que talvez eu seria mais feliz se eu tivesse feito de outa forma, e dessa forma você começa fazer uma autocrítica, uma autoanálise daquilo que você fez. E você consegue ver o que foi bom, o que deu certo, o que não deu tão certo, eu acho que é uma prática bem válida mesmo (ARESTA).

Podemos perceber que a experiência de gravar a aula proporcionou que Simetria observasse como foi contextualizado o conteúdo, o desenvolvimento das tarefas propostas e a participação dos alunos, oportunizando analisar suas ações e rever suas práticas de maneira atenciosa. Compreendemos que o registro da prática compartilhado 
permitiu reflexões e discussões sobre suas ações junto ao grupo, além de ter motivado a busca por novas estratégias de ensino, abrindo espaço para atividades mais significativas em futuras aulas, haja vista que a própria professora identificou que seu discurso, quando do momento das explicações dadas, ainda é muito centrado na figura do professor como detentor do saber, ou seja, reconheceu a necessidade de abrir mais espaço para o diálogo e a comunicação das e com as crianças.

Aresta pontuou que foi por meio do registro fotográfico que realizou uma narrativa escrita de sua aula. Embora não compartilhada no grupo, essa atividade de escrita de si para explicitar as imagens da aula possibilitou analisar e refletir sobre suas ações no sentido de identificar onde e como poderia melhorar a sua prática para que tivesse maior êxito ao ensinar seus alunos posteriormente, isso porque a professora tem consciência de que não é só em uma aula e/ou tarefa proposta que a experiência com a Geometria, especificamente sólidos, se esgota; existem outras possibilidades e elas serão aprimoradas com base no que temos realizado no trabalho coletivo.

Ao reconhecerem que o registro da aula trouxe reflexões que levam o professor a redirecionar suas ações, Simetria e Aresta parecem entrar num consenso de que é por meio da videogravação, embora pouco explorada no grupo, que o docente consegue avaliar melhor seu desempenho profissional.

Sobre o fazer docente, sem dúvida, é a videogravação; ela é a cópia de tudo o que aconteceu; se teve um aluno que respondeu errado, se teve um aluno que não entendeu e questiona; é pelo vídeo, então, sem dúvida, é a melhor forma de refletir sobra a prática. $O$ vídeo expõe mais a nossa prática a situação real mesmo [...] (SIMETRIA).

[...] é o vídeo mesmo, apesar de que eu não fiz nenhum ainda, eu só fiz a foto e a narrativa, mas eu acredito que o vídeo é o que mais mostra a sua cara, como está atuando, é isso aqui você [risos]. Porque ali você vai ver os pontos fortes, os pontos negativos e positivos com mais evidência. E você consegue retomar com mais clareza o que você fez na aula (ARESTA).

Verificamos, aqui, que ambas as professoras entendem que a vídeogravação é a ferramenta mais pertinente para retomar a prática vivenciada em sala de aula e que, por meio do vídeo, fica mais evidente quais os pontos que requerem mais atenção na hora de serem trabalhados, para que tanto o professor quanto o aluno tenham uma maior interação e consigam ensinar e aprender Matemática de forma mais exploratória e prazerosa. Ciríaco, Morelatti e Ponte (2016) esclarecem a importância do registro como objeto de análise e reflexão, pois permite ao professor problematizar e rever suas práticas abrindo espaço para refletir sobre si e sobre suas ações. Os autores ponderam que "A experiência de assistir o vídeo possibilita aprofundar a reflexão sobre a abordagem dos conteúdos matemáticos. [...]" (p. 255).

Nos casos analisados, mesmo que apenas uma delas tenha feito a opção pela videogravação, ao compartilhar sua prática isso não significa que a outra se exima do processo de reflexibilidade que o vídeo possibilita; isso é ilustrado no discurso de Aresta que, embora não tenha gravado nenhuma aula, já consegue verificar, ao avaliar Simetria, pensar formas de organização do trabalho pedagógico em Geometria, ou seja, 
as professoras aprendem por meio das práticas compartilhadas mesmo que não as tenham feito do mesmo modo. Sobre a percepção de sua inserção no grupo colaborativo, as docentes mencionam:

Eu me sinto privilegiada, acho que é um privilégio poder participar de um grupo com outros profissionais. Dali eu só tenho coisa para poder acrescentar para mim. Algumas vezes eu posso colaborar com alguma informação que eu tenho, mas a maioria das vezes eu estou aprendendo bastante, estou sugando tudo que está sendo compartilhado lá. Eu até comecei a fazer um registro assim, nas aulas que a gente tem aos sábados, tipo uma lista de atividades, de jogos; o professor cita várias, vocês citaram várias e elas [se referindo as demais professoras] também e se a gente não tomar nota, a gente esquece. Eu coloco o nome da atividade, eu desenho ela às vezes, e escrevo como se deu ela (SIMETRIA).

Eu acho que até essa troca mesmo, eu vejo assim que todo mundo está tão empenhado lá, está com clima gostoso, você leva, você mostra a realização da sua atividade, aquilo que causou, talvez que não foi bom, porque nós também colocamos lá: "olha eu fiz isso, mas eu não achei que foi legal". E depois você acaba revendo aquilo e você recebe ideias também tanto do nosso orientador, do professor, quanto das outras amigas que, às vezes, já fizeram e não deu certo e achou outro meio; então, para mim, está sendo ótimo (ARESTA).

Essas falas demonstram que, por meio do compartilhamento de experiências e pela troca de saberes, os professores contribuem para sua própria formação e para a formação dos demais profissionais. Para Cristovão (2009, p. 25), “O próprio ato de compartilhar torna-se uma tarefa reflexiva, pois preciso pensar como dizer sobre o que faço e depois preciso interpretar o que o outro está entendendo sobre o que eu digo". Ao compartilharem, desenvolvem a capacidade de questionar e refletir sobre sua própria prática e sobre o próprio caminho que está sendo percorrido. Refletir faz com que o professor vivencie suas ações e busque alternativas para melhorá-las.

Especificamente sobre as aulas de Geometria, objeto dos episódios das aulas compartilhadas neste artigo, indagamos se houve contribuições do grupo para um planejamento mais significativo e para práticas mais seguras, ao que obtivemos as seguintes manifestações:

Sem dúvida, eu estou há 3 anos no 40 ano. O primeiro ano que trabalhei no 40 ano a gente sempre cola no outro professor do 4 o ano, e como ela era uma professora que não tinha o hábito de trabalhar geometria, ela pulava esse conteúdo do livro. (...) eu tinha que seguir o referencial, mas a gente pulou e ela falava assim: deixa para o final, deixa para o final; mas esse final nunca chegou [risos] e aquela turma saiu sem aprender geometria. No próximo ano teve conteúdo de simetria e essa professora ainda estava lá, e eu coloquei no meu planejamento simetria, e como a gente trocava planejamento, ela me questionou: "Pra quê?" "Para que ficar desenhando?". E aquilo foi tirando essa cultura de trabalhar geometria da minha prática e eu só fui verificar a importância agora no grupo; aí eu lembro o quanto eu pequei nessa questão da geometria. (...) esse grupo veio só para acrescentar, porque como eu não fazia, eu comecei a colocar. A simetria era conteúdo do 1 o bimestre, mas eu trabalhei agora no terceiro; não importa, mas eu trabalhei. E eu pretendo até o último dia do ano trabalhar toda a geometria que é proposta no meu referencial, nem que eu tenha que migrar aula, fazer um projeto, alguma coisa que contemple todos os conteúdos (SIMETRIA). 
Com certeza, eu falo assim, até quando você vai preparar a tua aula, vai preparar a tua semana, o teu planejamento e você está participando de algum estudo nesse estilo (...) você dá mais ênfase, você pesquisa mais do que nos dias comuns. Eu acho assim, que todo mundo deveria passar por isso sempre, sempre, todo ano deveria ter uma coisa (...) parece que te força a buscar mais. Porque você quer fazer um bom trabalho, você quer mostrar um bom trabalho. Querendo ou não, isso te empurra vai te impulsando a fazer melhor (ARESTA).

Simetria pontua que buscou no grupo colaborativo apoio para suas angústias e fragilidades enfrentadas ao desenvolver conteúdos em sala de aula. Fica claro, na fala desta professora, que por falta de conhecimento, muitas vezes consequência de uma frágil formação inicial em termos de conhecimento específico de conteúdo da Matemática, neste caso de Geometria, deixou de desenvolver os conteúdos orientados no referencial da rede de ensino em que atua. A fala da professora revela que as práticas compartilhadas e problematizadas no contexto colaborativo contribuíram significativamente para que ela desenvolvesse atividades no campo da Geometria, como também para que se sentisse mais segura em suas ações em sala de aula, além de reconhecer a necessidade de articular o conhecimento escolar com as vivências dos alunos para articular os saberes.

Para Moraes e Pirola (2015, p. 63), "É importante que as atividades realizadas nas aulas tenham, na medida do possível e do interesse das crianças, vínculos com situações reais. [...]". Essa experiência significativa para os alunos, portanto, certamente contribui para gerar aprendizagem e atitudes mais positivas em relação à Matemática.

Para Aresta, a vinculação no grupo impulsiona a pesquisar e a buscar novas estratégias no sentido de ampliar as dimensões da prática educativa, sendo estas mais significativas para as aprendizagens dos alunos. Como analisado, no registro fotográfico compartilhado a professora desenvolveu atividades criativas e significativas relacionando a Geometria com a realidade dos alunos, ao incluir contextos do mundo real que podem ser representados por objetos geométricos. Para esta docente, o fator motivacional para o desenvolvimento de suas aulas de forma mais criativa, parece ser o elemento central da mudança em sua atuação. $O$ discurso nos mostra que ambas estão colaborando com o grupo pela vontade de aprender com o outro. No decorrer das reuniões, notamos que as professoras utilizaram ideias de atividades discutidas no grupo para desenvolver seus planejamentos.

Vimos, também, que o professor, ao estar interagindo e compartilhando ideias com o grupo, levanta questionamentos e reflexões que incidem a aprender consigo mesmo e com os demais ao se colocar como protagonista de sua formação e prática pedagógica, pois a inserção num espaço coletiva implica autonomia dos sujeitos e organização de seu pensamento para se fazer entendido/compreendido ao narrar suas histórias de aulas de Matemática, razão pela qual acreditamos na riqueza e não nos vemos desvinculados desta proposta de trabalho "com" os professores.

\section{CONCLUSÕES}

Os dados discutidos neste texto destacam que o compartilhamento do registro em um contexto colaborativo potencializa as práticas do aprender e ensinar Geometria por meio da colaboração e reflexão sobre as ações desencadeadas pelas professoras 
participantes deste processo formativo, uma vez que esta característica de trabalho levanta possibilidades de atuação diferenciadas quando discutidas e socializadas na perspectiva de ampliação do repertório didático-pedagógico dos sujeitos.

A percepção das docentes de "não ser mais a mesma professora" ou, ainda, de reconhecer mudanças em si mesmas, coloca em xeque a relevância da formação continuada em contexto, como o caso pesquisado, pois, neste momento, Simetria e Aresta estão em exercício profissional, ou seja, estão trabalhando com um conhecimento em ação, refletindo e buscando articular as vivências do grupo com suas respectivas práticas, o que pode dar e/ou trazer maiores possibilidades de êxito nas tarefas propostas e discutidas em suas turmas.

Em termos da participação efetiva e do engajamento na proposta, a coleta das informações pertinentes aos objetivos inicialmente propostos, mostram que todas as professoras se propuseram a colaborar com o mesmo envolvimento e compromisso, aumentando a possibilidade de transformações e mudanças positivas no decorrer no tempo.

O fato de registrarem e compartilharem suas práticas permitiu que as professoras retomassem suas ações de maneira cuidadosa, ao observarem mais a importância de se trabalhar questões específicas da Geometria com seus alunos e que o vocabulário próprio desta área precisa ser introduzido desde a infância. Assim, passaram a refletir e investigar suas próprias práticas em busca da melhoria do ensino. No ambiente da colaboração, as integrantes parecem ter rompido com o isolamento, com o individualismo, permitindo o diálogo entre os pares, reflexões e discussões pedagógicas visando o aprender a ensinar Matemática de forma coletiva. A participação das professoras neste contexto tem se mostrado potencializadora para reflexões sobre o próprio fazer, proporcionando ampliar os saberes e reorganizar estratégias significativas com novas possibilidades de abordagem da Geometria na Educação Básica.

Podemos notar que houve ressignificação de saberes e a ampliação de seus conhecimentos, e que este movimento de reflexão-ação-reflexão levou-as às mudanças não só em suas ações, mas, também, para dentro das escolas em que atuam, indicando, assim, que o espaço do grupo com características colaborativas está contribuindo para o desenvolvimento profissional dos integrantes, bem como para a melhoria da qualidade de ensino da Matemática.

Dentre as formas de registro adotadas e exploradas na análise de dados desta pesquisa, fica evidente o potencial formativo da videogravação, uma vez que a prática de análise das aulas leva o grupo a reviver o momento da vivência de sala de aula, fazendo uma autoanálise crítica dos processos de ensino adotados pelas professoras. Embora ainda pouco explorada, esta forma de registro instiga-nos a, em investigações futuras, nos apoiarmos mais nesta perspectiva metodológica para trabalhar a tematização da prática docente em um trabalho coletivo. Consideramos que o fortalecimento da interação e o diálogo entre as professoras, o professor universitário, acadêmicas e mestrandas, apontaram indicativos de conscientização das professoras em adotar práticas investigativas como caminho para a produção do conhecimento. 
Em síntese, embora o texto apresentado tenha como intenção destacar elementos da formação continuada de professores que ensinam Matemática no contexto de grupos colaborativos, a dinâmica instituída aqui pode vir a ser desenvolvida também em outras áreas, desde que respeitadas as especificidades de cada campo de atuação e os conhecimentos específicos dos componentes curriculares problematizados no espaço-tempo da colaboração. No quesito da inovação pedagógica, avaliamos que o principal contributo desta investigação seja o potencial que o recurso da videogravação das aulas, pelo professor, apresenta aos níveis reflexivos do trabalho docente, o que diferencia os dados produzidos na pesquisa aqui explorada de outras já publicadas anteriormente no campo da Educação Matemática, em particular.

\section{REFERÊNCIAS}

BOGDAN, Robert. BIKLEN, Sari. Investigação qualitativa e educação: uma introdução à teoria e aos métodos. Portugal: Porto Editora, 1994.

BROITMAN, Claudia; ITZCOVICH, Horacio. Geometria nas séries do ensino fundamental: problemas de seu ensino, problemas para seu ensino. In: PANIZZA, Mabel. Ensinar matemática na educação infantil $e$ nas séries iniciais: análise e proposta, 2006.

CIRÍACO, Klinger Teodoro. Professoras iniciantes e o aprender a ensinar Matemática em um grupo colaborativo. 2016. 334 f. Tese (Doutorado em Educação) - Faculdade de Ciências e Tecnologia da Universidade Estadual Paulista "Júlio de Mesquita Filho", FCT/Unesp, 2016.

CIRÍACO, Klinger Teodoro; MORELATTI, Maria Raquel Miotto. Notas sobre colaboração, grupos colaborativos e desenvolvimento profissional de professores iniciantes. In: CIRÍACO, Klinger Teodoro; RODRIGUES, Zionice Garbeline Martos (org.). Práticas de colaboração em contextos de formação com professores que ensinam matemática. Curitiba: CRV, 2016.

CIRÍACO, Klinger Teodoro; MORELATTI, Maria Raquel Miotto; PONTE, João Pedro da. Professoras iniciantes em grupo colaborativo: contributos da reflexão ao ensino de geometria. Zetetiké, Campinas, SP, v. 24, n. 2, maio/ago. 2016, p. 249-268, 2016. Disponível em: htt://periódicos.sbu.unicamp.br/ojs/index.php/ zetetike. Acesso em: mar. 2017.

CRISTOVÃO, Eliane Matesco. O papel da colaboração na construção de uma postura investigativa do professor de matemática. In: CARVALHO, Dione Lucchesi; CONTI, Keli Cristina (org.). Histórias de colaboração e investigação na prática pedagógica em matemática: ultrapassando os limites da sala de aula. Campinas, SP: Editora Alínea, 2009.

DAMIANI, Magda Floriana. Entendendo o trabalho colaborativo em educação e revendo seus benefícios. Educar, Curitiba, n. 31, 2008. Disponível em: http://www.scielo.br/pdf/er/n31/n31a13.pdf. Acesso em: maio 2017.

FERREIRA, Ana Cristina. O trabalho colaborativo como ferramenta e contexto para o desenvolvimento profissional: compartilhando experiências. In: NACARATO, Adair. Mendes; Paiva, Maria Auxiliadora Vilela (org.). A formação do professor que ensina matemática: perspectivas e pesquisas. 3. ed. Belo Horizonte: Autentica, 2013.

FERREIRA, Ana Cristina. Um olhar retrospectivo sobre a pesquisa brasileira em formação de professores de matemática. In: FIORENTINI, Dario (org.). Formação de professores de matemática: explorando novos caminhos com outros olhares. Campinas, SP: Mercado de Letras, 2003.

FIORENTINI, Dario (org.). Formação de professores de matemática: explorando novos caminhos com outros olhares. Campinas, SP: Mercado de Letras, 2003.

FIORENTINI, Dario; CRECCI, Vanessa Moreira. Práticas de desenvolvimento profissional sob a perspectiva dos professores. Revista Eletrônica da Divisão de Formação Docente, p. 71-72, 2012. Disponível em: http://www.seer.ufu.br/index.php/diversapratica. Acesso em: jun. 2017.

FONTANA, Maire Josiane; FÁVERO, Altair Alberto. Professor reflexivo: uma integração entre teoria e prática. Revista de Educação do Ideau, v. 8(17), p. 3, 2013. Disponível em: https://www.ideau.com.br/getulio/ restrito/upload/revistasartigos/30_1.pdf. Acesso em: jul. 2017.

IMBERNÓN, Francisco. Formação docente e profissional: formar-se para a mudança e a incerteza. 9. ed. São Paulo, Cortez, 2011. 
LÜDKE, Menga; ANDRÉ, Marli. E. D. A. Pesquisa em educação: abordagens qualitativas. São Paulo: Pedagógica e Universitária, 1986.

NACARATO, Adair Mendes. O grupo como espaço para a aprendizagem docente e compartilhamento de prática de ensino de matemática. In: NACARATO, Adair. Mendes. (org.). Prática docentes em educação matemática nos anos iniciais do ensino fundamental. Curitiba: Appris, 2013. p. 27-31.

NACARATO, Adair Mendes et al. Práticas compartilhadas de professoras dos anos iniciais do Ensino Fundamental num grupo de trabalho colaborativo. In: CIRÍACO, Klinger Teodoro; RODRIGUES, Zionice Garbelini Martos (org.). Práticas de colaboração em contextos de formação com professores que ensinam matemática. Curitiba: CRV, 2016.

NACARATO, Adair Mendes et. al. Professores e futuros professores compartilhando aprendizagens: dimensões colaborativas em processos de formação. In: NACARATO, Adair Mendes; PAIVA, Maria Auxiliadora Vilela (org.). A formação de professores que ensinam matemática: perspectivas e pesquisas. 3. ed. Belo Horizonte: Autentica, 2013.

MORAES, Maria Sueli Simão; PIROLA, Nelson Antônio. Atitudes positivas em relação à matemática. In: BRASIL. Ministério da Educação. Secretaria da Educação Básica. Pacto Nacional pela Alfabetização na Idade Certa. Alfabetização matemática na perspectiva do letramento. Caderno 7. Brasília: MEC; SEB, 2015. Disponível em: httt://pacto.mec.gov.br/images/pdf/cadernos_2005/cadernos_novembro/pnaic_ cad_7_19112015.pdf. Acesso em: maio 2017.

PAVANELLO, Regina Maria. A análise de episódios de ensino e a formação do professor reflexivo. In: GUIMARÃES, Rute Borba (org.). Reflexões sobre o ensino de matemática nos anos iniciais de escolarização. Recife: SBEM, 2009.

RODRIGUES, Zionice Garbelini Martos et al. Grupo colaborativo de educação matemática e cientifica: a experiência de um trabalho colaborativo para o desenvolvimento do currículo oficial do estado de São Paulo. In: CIRÍACO, Klinger Teodoro; RODRIGUES, Zionice Garbelini Martos (org.). Práticas de colaboração em contextos de formação com professores que ensinam matemática. Curitiba: CRV, 2016.

SEVERINO, Antônio Joaquim. Metodologia do trabalho científico: teoria e prática cientifica. 23. ed. rev. e atual. São Paulo: Cortez, 2007. 